\title{
Whole-genome DNA methylation and hydroxymethylation profiling for HBV-related hepatocellular carcinoma
}

\author{
CHAO YE* , RAN TAO*, QINGYI CAO, DANHUA ZHU, YINI WANG, \\ JIE WANG, JUAN LU, ERMEI CHEN and LANJUAN LI \\ State Key Laboratory for Diagnosis and Treatment of Infectious Diseases, \\ Collaborative Innovation Center for Diagnosis and Treatment of Infectious Diseases, The First Affiliated Hospital, \\ College of Medicine, Zhejiang University, Hangzhou, Zhejiang 310000, P.R. China
}

Received March 18, 2016; Accepted May 13, 2016

DOI: $10.3892 /$ ijo.2016.3535

\begin{abstract}
Hepatocellular carcinoma (HCC) is a common solid tumor worldwide with a poor prognosis. Accumulating evidence has implicated important regulatory roles of epigenetic modifications in the occurrence and progression of $\mathrm{HCC}$. In the present study, we analyzed 5-methylcytosine (5-mC) and 5-hydroxymethylcytosine $(5-\mathrm{hmC})$ levels in the tumor tissues and paired adjacent peritumor tissues (APTs) from four individual HCC patients using a (hydroxy)methylated DNA immunoprecipitation approach combined with deep sequencing [(h)MeDIP-Seq]. Bioinformatics analysis revealed that the 5-mC levels in the promoter regions of 2796 genes and the 5-hmC levels in 507 genes differed significantly between HCC tissues and APTs. These differential genes were grouped into various clusters and pathways and found to be particularly enriched in the 'Metabolic pathways' that include 'Glycolysis/ gluconeogenesis', 'Oxidative phosphorylation' and 'Citrate cycle (TCA cycle)', implicating a potential role of metabolic alterations in HCC. Furthermore, 144 genes had both 5-mC and 5-hmC changes in HCC patients, and 10 of them (PCNA, MDM2, STAG1, E2F4, FGF4, FGF19, RHOBTB2, UBE2QL1, DCN and HSP90AA1) were enriched and interconnected in five pathways including the 'Cell cycle', 'Pathway in cancer', 'Ubiquitin mediated proteolysis', 'Melanoma' and 'Prostate cancer' pathways. The genome-wide mapping of 5-mC and 5-hmC in HCC tissues and APTs indicated that both 5-mC and 5 -hmC epigenetic modifications play important roles in the regulation of $\mathrm{HCC}$, and there may be some interconnec-
\end{abstract}

Correspondence to: Professor Lanjuan Li, State Key Laboratory for Diagnosis and Treatment of Infectious Diseases, Collaborative Innovation Center for Diagnosis and Treatment of Infectious Diseases, The First Affiliated Hospital, College of Medicine, Zhejiang University, No. 79 Qinchun Road, Hangzhou, Zhejiang 310000 P.R. China E-mail: ljli@zju.edu.cn

*Contributed equally

Key words: hepatocellular carcinoma, 5-methylcytosine, 5-hydroxymethylcytosine, (h)MeDIP-Seq, epigenetics, genome-wide, metabolic tions between them. Taken together, in the present study we conducted the first genome-wide mapping of DNA methylation combined with hydroxymethylation in HBV-related HCC and provided a series of potential novel epigenetic biomarkers for HCC.

\section{Introduction}

Hepatocellular carcinoma (HCC), a common solid tumor, is the third most frequent cause of cancer-related death in the world. Hepatitis B virus (HBV) infection is the main cause of HCC in China (1). Individuals with chronic HBV infection, especially those who have progressed to chronic liver disease and cirrhosis, are at high risk of developing HCC $(2,3)$. Most HCC patients are diagnosed at their advancing stage and refractory to chemotherapy and radiotherapy $(4,5)$. Even if the patients receive liver transplantation, the recurrence rate is still high (6).

Epigenetic modifications are found to play important roles in various biological processes especially in cancer development (7). Methylation of DNA at 5-position of cytosines $(5-\mathrm{mC})$ is a key epigenetic mark that has been extensively studied in many types of malignancies (8). Aberrant DNA methylation of promoter $\mathrm{CpG}$ islands has been associated with global hypomethylation and specific loci hypermethylation, which has the potential to become diagnostic markers for the progression of malignant tumors (9). 5-mC can be converted to 5-hydroxymethylcytosine $(5-\mathrm{hmC})$ by the ten-eleven translocation (TET) family proteins. In mammals, $5-\mathrm{hmC}$ is detected in almost all tissues and cell types $(10,11)$. Emerging evidence has shown that 5-hmC and TET family might serve unique biological roles in many biological processes such as gene expression regulation, gene transcription and DNA methylation regulation $(12,13)$. Several studies have found $5-\mathrm{hmC}$ alternations in the epigenetic regulation of various diseases, including cancer (14).

Studies of DNA methylation changes in HCC have led to the identification of several candidate methylated genes as potential tumor biomarkers $(15,16)$, yet, little is known about hydroxymethylation distribution in HCC. In previous studies, DNA methylation was determined using methylation sensitive polymerase chain reaction combined bisulfite restriction 
Table I. Clinicopathological features for the four HCC patients included in the study.

\begin{tabular}{lcccc}
\hline Variables & SAM 1 & SAM 2 & SAM 3 & SAM 4 \\
\hline Case number & 560 & 629852 & 716677 & 717323 \\
Age (years) & 41 & 53 & 40 & 57 \\
Gender & Male & Male & Male & Male \\
ALT (U/l) & 35 & 30 & 54 & 34 \\
AFP(ng/ml) & 2 & $>50000$ & 12628.5 & 8241 \\
HBV-DNA & $10^{4}$ & $10^{3}$ & $10^{3}$ & $10^{3}$ \\
Tumor size $(\mathrm{cm})$ & $2 \times 2$ & $7.5 \times 8$ & $3.5 \times 3$ & $8.5 \times 8.5$ \\
Tumor number & Single & Multiple & Single & Single \\
PVTT & No & Yes & Yes & Yes \\
Grade & Moderate & Poor & Moderate & Moderate \\
\hline
\end{tabular}

PVTT, portal vein tumor thrombus.

analysis (COBRA) or bisulfite sequencing techniques. With the development of high-throughput sequencing technologies, the whole-genome DNA (hydroxy)methylation profiling in cancer has generated data with significantly higher quantity and quality $(17,18)$. However, most existing studies of DNA methylation in HCC employed Infinium HumanMethylation BeadChip Arrays or Methylation Microarray $(19,20)$, which may have some limitations on resolution and scope. A novel method termed (hydroxy)methylated DNA immunoprecipitation sequencing [(h)MeDIP-Seq], combining DNA immunoprecipitation with high-throughput sequencing, has emerged as an advantageous tool for identifying (hydroxy) methylated $\mathrm{CpG}$-rich sequences in a much faster and more sensitive manner than ever before.

In an attempt to explore the $5-\mathrm{mC} / 5-\mathrm{hmC}$ changes in $\mathrm{HCC}$, we performed a genome-wide mapping of $5-\mathrm{mC} / 5-\mathrm{hmC}$ in four paired $\mathrm{HCC}$ tissues and adjacent peritumor tissues (APTs) using MeDIP-Seq/hMeDIP-Seq.

\section{Materials and methods}

Clinical samples. Total of 4 fresh-frozen primary HCC tissues and paired APTs were included in MeDIP-Seq/ hMeDIP-Seq. The collected cancer tissues were excised within the margins of the cancer lesion, and the APTs were collected from a location at least $3 \mathrm{~cm}$ distant from the tumor boundaries. All the collections followed the same protocol. All of the cancerous tissues were diagnosed as primary hepatocellular carcinoma, provided by two independent and experienced pathologists. Fresh-frozen HCC tissues and APTs were collected during the surgical resection.

The four HCC patients were HBV surface antigen-positive without hepatitis $\mathrm{C}$ virus (HCV) infection and exhibited the same cirrhosis etiology. Retrospectively data were collected including demographic, preoperative laboratory and pathological parameters from electronic medical records, and are summarized in Table I.

DNA extraction. Genomic DNA was extracted from frozen HCC tissues and paired APTs using the DNeasy Blood and
Tissue kit (Qiagen; 69504) according to the manufacturer's protocol. Briefly, tissues were homogenized using a hand-held homogenizer, digested with Proteinase K (Qiagen; 69504) and RNase A (Qiagen; 19101) overnight at $56^{\circ} \mathrm{C}$, precipitated and washed. Concentration and purity of DNA were measured using a NanoDrop 1000 Spectrophotometer (Thermo Fisher Scientific, Waltham, MA, USA).

MeDIP-seq and hMeDIP-seq. As previously described $(21,22)$, the genomic DNA was fragmented using a Covaris sonication system (Covaris, Woburn, MA, USA) according to the parameters. After sonication, the fragments were denatured to produce single stranded DNA (ssDNA). Following denaturation, the ssDNA was incubated with anti-5-mC antibody or anti-5-hmC antibody. The antibody-DNA complexes were captured by protein A/G beads, and the MeDIP and hMeDIP products were collected for sequencing with $\mathrm{HiSeq}^{\mathrm{TM}} 2000$ sequencing system (Illumina, Inc., San Diego, CA, USA).

Identification of differential methylation/hydroxymethylation regions (DMR/DHMR). DMR and DHMR identification are based on reads per kilo base of transcript per million mapped reads (RPKM)-normalized to 5-mC and 5-hmC density, used model-based analysis of ChIP-Seq (MACS).

Functional enrichment analysis. Functional enrichment analysis is for the genes associated with DMRs and DHMRs. Gene Ontology (GO) (https://david.ncifcrf.gov/) is a standard classification system inferring gene function and gene products. PANTHER website (http://go.pantherdb.org/) and Kyoto Encyclopedia of Genes and Genomes (KEGG) pathway analysis (Web-based Gene Set Analysis Tool Kit and http:// www.kegg.jp/kegg/pathway.html) were also used suggesting physiological functions of these genes.

Ethics statement. All experimental protocols and study methods were approved by the Ethics Committee of the First Affiliated Hospital, School of Medicine, Zhejiang University. The written consent was received from each participant in the present study at the time of surgery.

\section{Results}

Global DNA (hydroxy)methylation changes in HCC tissues and APTs. We isolated total genomic DNA from the 4 HCC tumor tissues and paired APTs, and employed (h)MeDIP-seq to explore genome-wide 5-mC and 5-hmC profiles for the 8 samples. In total, MACS identified 4.52 million reads and 6.0 million reads of sequencing data for $5-\mathrm{mC}$ and $5-\mathrm{hmC}$, respectively (Table II). Differential 5-mC and 5-hmC peaks between HCC tumor tissues and paired APTs are shown in Table III. Density distribution of these peaks on the whole genome is shown in Fig. 1. 5-mC and 5-hmC peak enrichment profiles of HCC tumor tissues compared with APTs in genomic areas were shown in Fig. 2. Both $\mathrm{CvP}$ and $\mathrm{PvC}$ differential peaks of 5-mC were enriched in X5UTR and Exon. 5-hmC peak enrichment seemed average in each genomic features.

Analysis of DMR and hDMR-associated genes in promoter regions. Promoter region is an important gene regulation 

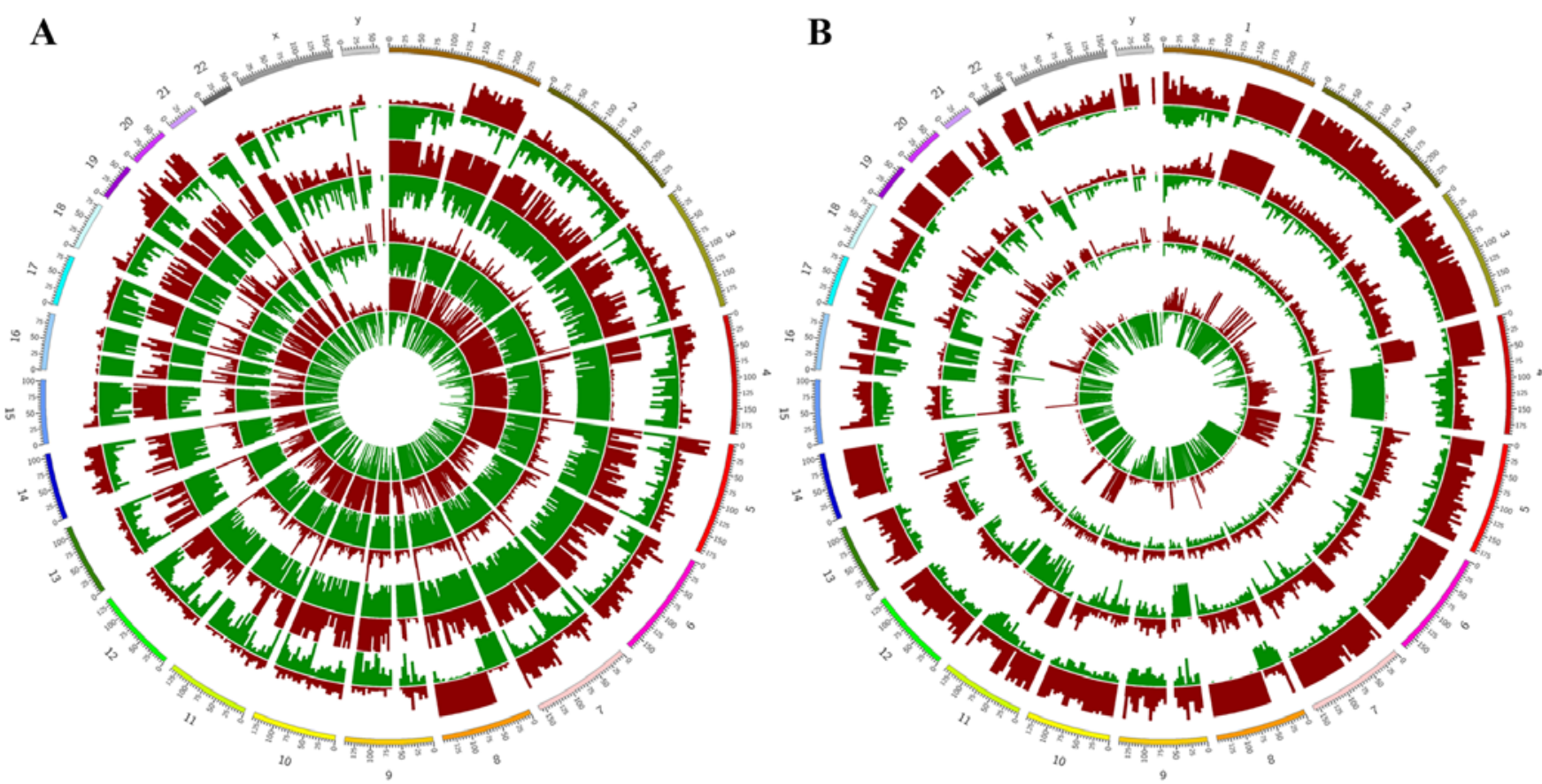

Figure 1. (A) Density distribution of 5-mC peaks on each chromosome. (B) Density distribution of 5-hmC peaks on each chromosome. From the outside to the inside, SAM-716677, SAM-717323, SAM-629852, SAM-560, respectively. Red, peaks upregulated in HCC tumor tissues compared with paired APTs. Green, peaks downregulated in HCC tumor tissues compared with paired APTs (calculated the peaks number in each five mb).

Table II. Number of reads generated by (h)MeDIP-Seq for each sample.

\begin{tabular}{lccccc}
\hline & & $560(\mathrm{P} / \mathrm{T})$ & $629852(\mathrm{P} / \mathrm{T})$ & $716677(\mathrm{P} / \mathrm{T})$ & $717323(\mathrm{P} / \mathrm{T})$ \\
\hline MeDIP-Seq & & & & & \\
Total number of reads & $\mathrm{P}$ & $178,832,47$ & $288,179,93$ & 22939802 & 20338428 \\
& $\mathrm{~T}$ & $176,540,07$ & $204,678,83$ & 21452236 & 31407738 \\
Total number of mapped read & $\mathrm{P}$ & $129,391,26$ & $222,400,94$ & 21408527 & 16080416 \\
& $\mathrm{~T}$ & $152,462,39$ & $160,719,42$ & 19448683 & 28980186 \\
Mapping rate (\%) & $\mathrm{P}$ & $72.35 \%$ & $77.17 \%$ & $93.32 \%$ & $79.06 \%$ \\
hMeDIP-Seq & $\mathrm{T}$ & $86.36 \%$ & $78.52 \%$ & $90.66 \%$ & $92.27 \%$ \\
Total number of reads & & & & & $316,801,82$ \\
& $\mathrm{P}$ & $251,088,30$ & $299,964,13$ & $340,096,74$ & $269,660,39$ \\
Total number of mapped reads & $\mathrm{T}$ & $340,606,22$ & $314,499,77$ & $265,629,54$ & $239,597,42$ \\
& $\mathrm{P}$ & $191,931,19$ & $248,284,70$ & $265,222,32$ & $214,664,23$ \\
Mapping rate (\%) & $\mathrm{T}$ & $266,231,98$ & $247,343,23$ & $213,428,28$ & $75.63 \%$ \\
& $\mathrm{P}$ & $76.44 \%$ & $82.77 \%$ & $77.98 \%$ & $79.60 \%$ \\
\hline
\end{tabular}

Table III. Differentially expressed peaks of 5-mC and 5-hmC MACS of each paired samples.

\begin{tabular}{lcccr}
\hline Samples & MeDIP-CvP & MeDIP-PvC & hMeDIP-CvP & hMeDIP-PvC \\
\hline 560 & 51475 & 44772 & 14853 & 53739 \\
629852 & 9137 & 35823 & 9061 & 5748 \\
717323 & 70363 & 87400 & 16464 & 17036 \\
716677 & 17408 & 23586 & 42497 & 9332 \\
\hline
\end{tabular}

CvP, upregulated peaks in HCC tumor tissues compared with paired APTs; PvC, downregulated peaks in HCC tumor tissues compared with paired APTs. 

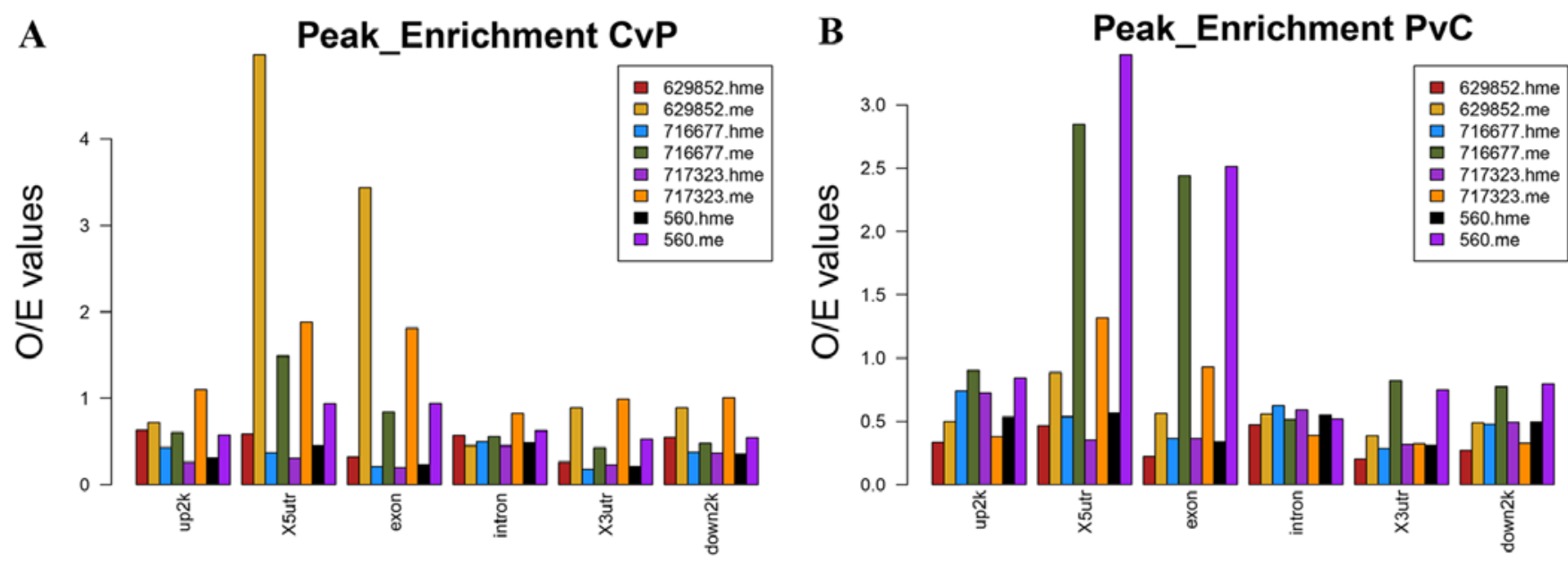

Figure 2. Enrichment of 5-mC and 5-hmC peaks of HCC tissues compared with APTs in genomic areas. (A) Upregulated peaks of 5-mC and 5-hmC in HCC tissues compared with APTs (CvP), (B) downregulated peaks of 5-mC and 5-hmC in HCC tissues compared with APTs (PvC). O/E, obtain/expect. O/E >1 means peaks relatively significant enriched area.
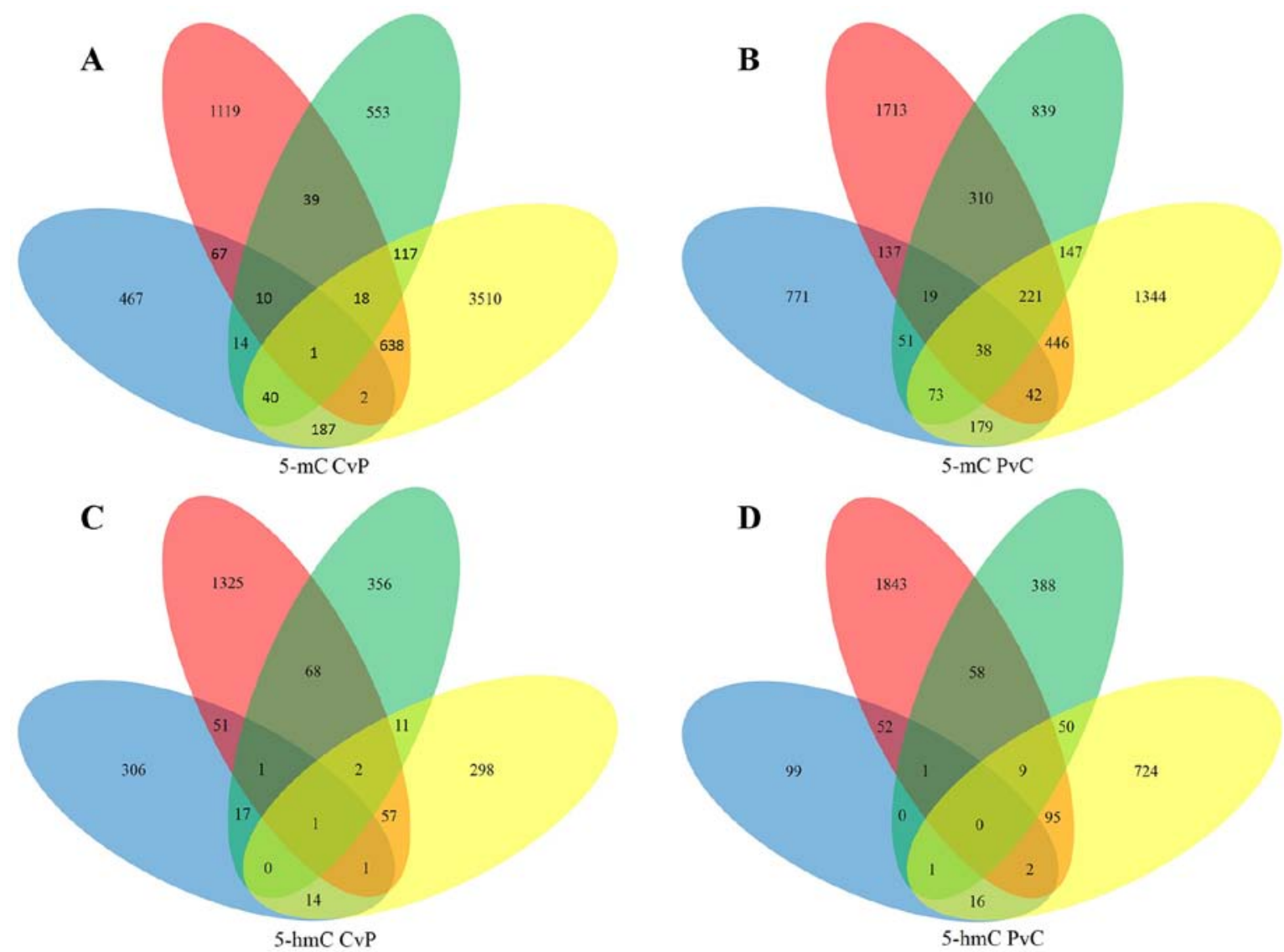

Figure 3. Composition of DMR and DHMR-associated genes in four paired samples. (A) A total of 1133 hypermethylated genes were found in at least two samples (5-mC CvP); (B) 1663 hypomethylated genes were found in at least two (5-mC PvC); (C) 223 upregulated 5-hmC genes were found in at least two samples (5-hmC CvP); (D) 284 downregulated 5-hmC genes in HCC tissues compared to APTs were found in at least two samples (5-hmC PvC). Blue, SAM-560; red, SAM-629852; green, SAM-716677; yellow, SAM-717323.

region, and the methylation or demethylation at this region plays a key regulatory role in gene expression. In the present study, we carried out further bioinformatics analysis to identify locus-specific DMRs and hDMRs between HCC tumor tissues and APTs in the promoter region $(-3.5 \mathrm{~K}$ to $+1.5 \mathrm{~K}$ of TSS). The total differential 5-mC peaks (DMRs) that exhib- ited significant difference between the two groups ( $>2$-fold, $\mathrm{P}<0.05)$ were associated with nearly 4097 genes in terms of RefSeq ID. Of the four samples, 1924, 788, 4521 and 734 genes had hypermethylation (5-mC-CvP) at their promoters while 2956, 1667, 2490 and 1310 genes had hypomethylation (5-mC-PvC), respectively (Table IV). 

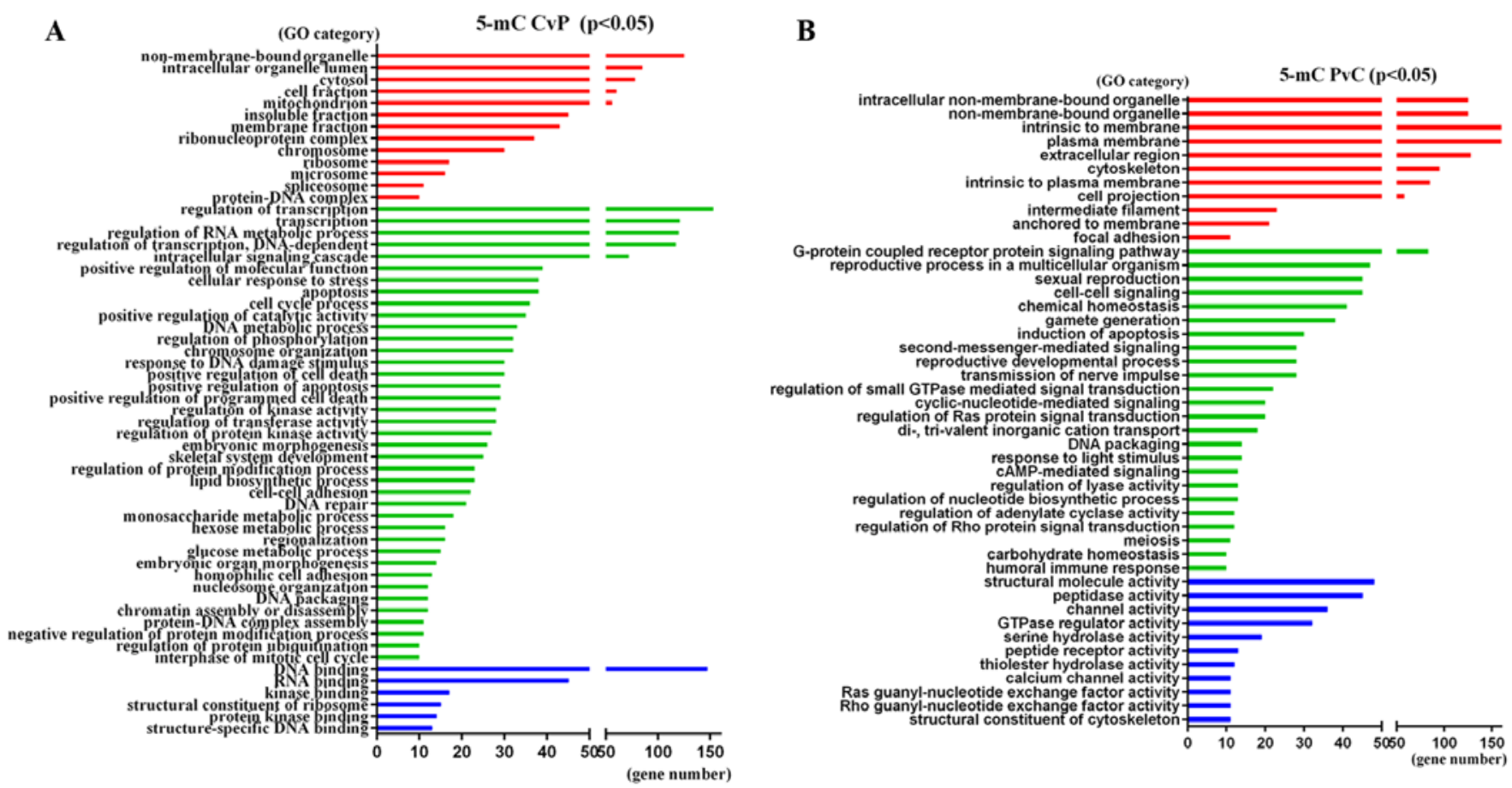

Figure 4. (A) The significant GO categories of hypermethylated genes (5-mC CvP) in HCC tissues compared with APTs; (P<0.05). (B) The significant GO categories of hypomethylated genes $(5-\mathrm{mC} \mathrm{PvC})$ in HCC tissues compared with APTs $(\mathrm{P}<0.05)$. (Red, cellular component; green, biological process; blue, molecular function).

Table IV. Numbers of DMRs and hDMRs associated genes.

Samples 5-mC-CvP 5-mC-PvC 5-hmC-CvP 5-hmC-PvC

\begin{tabular}{lrrrr}
\hline 560 & 1924 & 2957 & 385 & 2061 \\
629852 & 734 & 1310 & 457 & 171 \\
717323 & 4521 & 2490 & 391 & 897 \\
716677 & 788 & 1667 & 1506 & 507 \\
\hline
\end{tabular}

CvP, upregulated genes in $\mathrm{HCC}$ tumor tissues compared with paired APTs; PvC, downregulated genes in HCC tumor tissues compared with paired APTs.

The same analysis was carried out to search for differential 5-hmC peaks (DHMRs) between HCC tumor tissues and APTs in the promoter. An average of 1593 genes were associated. Genes (385, 1506, 391 and 457) showed higher 5-hmC levels (5-hmC-CvP) in the promoter in HCC tissues compared with APTs of the four samples, while 2061, 507, 897 and 171 genes showed lower 5-hmC levels (5-hmC-PvC), respectively. (Table IV).

Functional enrichment analysis of 5-mC and 5-hmC associated genes. A total of $11335-\mathrm{mC}-\mathrm{CvP}$ genes and 1663 5-mC-PvC genes were found in at least two samples (Fig. 3A and B). The significant GO categories of these genes are shown in Fig. $4(\mathrm{P}<0.05)$. The most enriched term of 5-mC-CvP genes is 'Transition metal ion binding' (GO:0046914, P=7.20E-06), 'Regulation of RNA metabolic process' (GO:0051252, $\mathrm{P}=4.10 \mathrm{E}-05)$ and 'DNA binding'
(GO:0003677, $\mathrm{P}=4.60 \mathrm{E}-05$ ), while the 5-mC-PvC genes were enriched in 'Plasma membrane' (GO:0005886, $\mathrm{P}=2.80 \mathrm{E}-05)$, 'Keratin filament' (GO:0045095, $\mathrm{P}=6.50 \mathrm{E}-05)$ and 'Cyclic-nucleotide-mediated signaling' (GO:0019935, $\mathrm{P}=8.70 \mathrm{E}-05$ ).

The KEGG pathway analysis showed that the significantly differential hypermethylated genes were enriched in several pathways such as 'Metabolic pathways' (adjP=0.0021) (such as GBE1, GALNT6, NDUFS6, HEXB, RRM1 and CKMT2) and 'Pathways in cancer' (adjP=0.0027) (such as CDKN2A, CDKN2B, APC, GSTP1, DAPK3, FADD, FGF4 and FGF19), while differential hypomethylated genes were enriched in 'Neuroactive ligand-receptor interaction' (adjP=0.0011) (such as P2RY4, SSTR5, AVPR2, MAS1, NTSR1 PRSS3, GHSR and CALCRL) and 'Calcium signaling pathway' (adjP=0.0140) (such as ATP2B3, RYR1, NTSR1, NOS1, HTR5A, SLC25A31, GNAS and DRD5). In Table $V$ all significant KEGG pathways $($ adjp<0.05) are listed. For protein class by PANTHER website, both hypermethylated and hypomethylated genes were mainly associated with 'Nucleic acid binding', 'Hydrolase' and 'Receptor' (Fig. 5).

Next, DHMRs between HCC tumor tissues and APTs in the promoter were subjected to the same analysis. A total of 223 5-hmC-CvP genes and 284 5-hmC-PvC genes were found in at least two samples (Fig. 3C and D). The most significant GO categories of 5-hmC-CvP genes were 'Plasma membrane' (GO:0005886, p=3.10E-05), 'G-protein coupled receptor protein signaling pathway' (GO:0007186, $\mathrm{P}=3.60 \mathrm{E}-03$ ) and 'Intrinsic component of membrane' (GO:0031224, $\mathrm{P}=1.10 \mathrm{E}-02) .5$-hmC-PvC genes were enriched in 'Cytosol' (GO:0005829, $\mathrm{P}=3.10 \mathrm{E}-02)$, 'Nucleoplasm part' (GO:0044451, $\mathrm{P}=1.90 \mathrm{E}-02)$ and 'Transcription factor complex' (GO:0005667, 
Table V. KEGG pathway analysis of hypermethylated and hypomethylated genes.

A, KEGG pathway analysis of hypermethylated genes

\begin{tabular}{|c|c|c|c|}
\hline Pathway name & ID & Gene & EntrezGene \\
\hline $\begin{array}{l}\text { Regulation of actin } \\
\text { cytoskeleton }\end{array}$ & 04810 & 20 & $\begin{array}{l}\text { WASF2, GNG12, NRAS, FGF4, APC, CYFIP2, } \\
\text { PDGFB, FGF19, MAP2K2, TIAM2, ARHGAP35, } \\
\text { GNA12, PIK3R5, TMSB4Y, ARHGEF1, PPP1CA, } \\
\text { ITGB4, RRAS2, ACTN3, MYL12B }\end{array}$ \\
\hline $\begin{array}{l}\text { Systemic lupus } \\
\text { erythematosus }\end{array}$ & 05322 & 15 & $\begin{array}{l}\text { HIST1H4F, HIST1H4K, HIST1H2BM, H2AFY, } \\
\text { HIST1H2BI, ELANE, HIST1H2AL, HIST3H2BB, } \\
\text { HIST1H3G, ACTN3, TROVE2, HIST3H2A, } \\
\text { HIST1H3J, HIST1H2AJ, HIST1H4H }\end{array}$ \\
\hline Metabolic pathways & 01100 & 51 & $\begin{array}{l}\text { GBE1, GALNT6, NDUFS6, HEXB, RRM1, } \\
\text { CKMT2, GDA, BCAT1, RPE, GLUL, SDHA, } \\
\text { HYAL2, CYP51A1, NDUFV1, HMGCS1, NDUFA2, } \\
\text { CYP4F11, CTPS1, SUCLG2, POLR3C, DGAT1, } \\
\text { LDHB, HMGCR, B3GALT6, ALOX12, MGAT4B, } \\
\text { SMPD1, TBXAS1, AK4, BST1, POLG2, HYAL4, } \\
\text { DGKE, POLR3G, GALNT3, AK1, ATP6V1D, } \\
\text { SGSH, TCIRG1, B3GAT2, PC, DCXR, DHRS9, } \\
\text { CEPT1, PLCB4, SQLE, ACADM, GPI, PTDSS1, } \\
\text { UGT2B7, ALOX15B }\end{array}$ \\
\hline
\end{tabular}

Pathways in cancer 0520021 CDKN2B, NRAS, LAMC1, FGF4, DVL3, CTBP2, APC, PDGFB, GSTP1, FGF19, MAP2K2, DAPK3, FADD, FZD7, CSF3R, BMP2, LEF1, PIK3R5, MSH3, BMP4, CDKN2A

Gastric acid

secretion

Purine metabolism

$04971 \quad 8$

ADCY6, PLCB4, SLC4A2, CFTR, ADCY5, KCNJ1, KCNJ15, CALML6

Pancreatic secretion

Melanoma

Tight junction

Basal cell

carcinoma

Cell cycle

Glioma

Vascular smooth muscle contraction

Glutathione

metabolism

Insulin signaling

pathway

Oocyte meiosis
$00230 \quad 12$

04972

9

05218

7

$04530 \quad 10$

0521

$04270 \quad 8$

$05217 \quad 6$

$04110 \quad 9$

CDKN2B, PCNA, STAG1, YWHAZ, ORC1, TFDP2, CDC23, CDKN2A, ORC6

AK1, PDE4A, ADCY5, PDE7A, RRM1, AK4 ADCY6, GDA, PDE4D, POLR3C, PDE3B, POLR3G

ADCY6, PLCB4, CELA2A, SLC4A2, CFTR, CELA3B, BST1, ADCY5, ATP2B1 CDKN2A

NRAS, PRKCZ, MPP5, CTTN, RRAS2, ACTN3, CLDN14, MYL12B, TJAP1, CLDN11

BMP2, DVL3, APC, LEF1, BMP4, FZD7

NRAS, PDGFB, PIK3R5, MAP2K2, CDKN2A, CALML6

GNA12, ADCY5, ARHGEF1, CALML6, PLCB4, ADCY6, PPP1CA, MAP2K2

004805 OPLAH, GPX7, GSTP1, GSTM4, RRM1

$04910 \quad 9$

PRKAG2, NRAS, PIK3R5, PRKCZ, CALML6, PPP1CA, PDE3B, MAP2K2, PRKAR1A

SPDYA, ADCY5, SLK, CALML6, ADCY6, YWHAZ, PPP1CA, CDC23

$\mathrm{C}=136 ; \mathrm{O}=15 ; \mathrm{E}=3.43 ; \mathrm{R}=4.37$; rawP $=1.96 \mathrm{e}-06 ; \operatorname{adj} \mathrm{P}=0.0001$

$\mathrm{C}=1130 ; \mathrm{O}=51 ; \mathrm{E}=28.51 ; \mathrm{R}=1.79$; raw $\mathrm{P}=5.73 \mathrm{e} 05 ; \operatorname{adj} \mathrm{P}=0.0021$

$\mathrm{C}=326 ; \mathrm{O}=21 ; \mathrm{E}=8.22 ; \mathrm{R}=2.55$ $\operatorname{raw} \mathrm{P}=9.84 \mathrm{e} 05 ; \operatorname{adj} \mathrm{P}=0.0027$

$\mathrm{C}=74 ; \mathrm{O}=8 ; \mathrm{E}=1.87 ; \mathrm{R}=4.29$; rawP $=0.0006 ; \operatorname{adj} \mathrm{P}=0.0133$

$\mathrm{C}=162 ; \mathrm{O}=12 ; \mathrm{E}=4.09 ; \mathrm{R}=2.94$; $\operatorname{raw} \mathrm{P}=0.0009 ; \mathrm{adj} \mathrm{P}=0.0148$

$\mathrm{C}=101 ; \mathrm{O}=9 ; \mathrm{E}=2.55 ; \mathrm{R}=3.53$; $\operatorname{rawP}=0.0011 ; \operatorname{adj} \mathrm{P}=0.0148$

$\mathrm{C}=71 ; \mathrm{O}=7 ; \mathrm{E}=1.79 ; \mathrm{R}=3.91$; $\operatorname{rawP}=0.0021 ; \operatorname{adj} \mathrm{P}=0.0194$

$\mathrm{C}=132 ; \mathrm{O}=10 ; \mathrm{E}=3.33 ; \mathrm{R}=3.00$; $\operatorname{rawP}=0.0020 ; \operatorname{adj} \mathrm{P}=0.0194$

$\mathrm{C}=55 ; \mathrm{O}=6 ; \mathrm{E}=1.39 ; \mathrm{R}=4.32$; $\operatorname{rawP}=0.0026 ; \operatorname{adj} \mathrm{P}=0.0222$

$\mathrm{C}=124 ; \mathrm{O}=9 ; \mathrm{E}=3.13 ; \mathrm{R}=2.88$; $\operatorname{raw} \mathrm{P}=0.0043 ; \operatorname{adj} \mathrm{P}=0.0341$

$\mathrm{C}=65 ; \mathrm{O}=6 ; \mathrm{E}=1.64 ; \mathrm{R}=3.66$; $\operatorname{raw} \mathrm{P}=0.0059 ; \operatorname{adj} \mathrm{P}=0.0409$

$\mathrm{C}=116 ; \mathrm{O}=8 ; \mathrm{E}=2.93 ; \mathrm{R}=2.73$; rawP=0.0093; $\operatorname{adj} \mathrm{P}=0.0492$

$\mathrm{C}=50 ; \mathrm{O}=5 ; \mathrm{E}=1.26 ; \mathrm{R}=3.96$; $\operatorname{raw} \mathrm{P}=0.0084 ; \operatorname{adj} \mathrm{P}=0.0492$

$\mathrm{C}=138 ; \mathrm{O}=9 ; \mathrm{E}=3.48 ; \mathrm{R}=2.59$; $\operatorname{rawP}=0.0085 ; \operatorname{adj} \mathrm{P}=0.0492$

$\mathrm{C}=112 ; \mathrm{O}=8 ; \mathrm{E}=2.83 ; \mathrm{R}=2.83$; $\operatorname{raw} \mathrm{P}=0.0076 ; \operatorname{adj} \mathrm{P}=0.0492$ 
Table V. Continued.

B, KEGG pathway analysis of hypomethylated genes

\begin{tabular}{|c|c|c|c|c|}
\hline Pathway name & ID & Gene & EntrezGene & Statistic \\
\hline $\begin{array}{l}\text { Neuroactive } \\
\text { ligand-receptor } \\
\text { interaction }\end{array}$ & 04080 & 26 & $\begin{array}{l}\text { P2RY4, SSTR5, AVPR2, MAS1, NTSR1, PRSS3, } \\
\text { GHSR, CALCRL, CHRM4, F2RL3, HTR5A, } \\
\text { GRM8, HTR1D, SSTR3, DRD5, GABRB3, } \\
\text { P2RX6, CNR1, GRM4, LEP, UTS2R, SSTR4, } \\
\text { MC5R, ADRA2B, PARD3, HRH1 }\end{array}$ & $\begin{array}{l}\mathrm{C}=272 ; \mathrm{O}=26 ; \mathrm{E}=10.05 ; \mathrm{R}=2.59 ; \\
\operatorname{rawP}=1.10 \mathrm{e} 05 ; \operatorname{adj} \mathrm{P}=0.0011\end{array}$ \\
\hline $\begin{array}{l}\text { Dilated } \\
\text { cardiomyopathy }\end{array}$ & 05414 & 11 & $\begin{array}{l}\text { GNAS, SGCA, TPM2, CACNA1C, ADCY5, } \\
\text { CACNB2, ADCY9, TPM4, ADCY6, } \\
\text { CACNA2D4, ADCY7 }\end{array}$ & $\begin{array}{l}\mathrm{C}=90 ; \mathrm{O}=11 ; \mathrm{E}=3.33 ; \mathrm{R}=3.31 \\
\text { raw } \mathrm{P}=0.0005 ; \operatorname{adj} \mathrm{P}=0.0098\end{array}$ \\
\hline Bile secretion & 04976 & 10 & $\begin{array}{l}\text { GNAS, SLC4A5, KCNN2, ADCY5, ATP1A4, } \\
\text { ADCY9, ADCY6, HMGCR, ADCY7, AQP8 }\end{array}$ & $\begin{array}{l}\mathrm{C}=71 ; \mathrm{O}=10 ; \mathrm{E}=2.62 ; \mathrm{R}=3.81 \\
\operatorname{rawP}=0.0003 ; \operatorname{adj} \mathrm{P}=0.0098\end{array}$ \\
\hline $\begin{array}{l}\text { Calcium signaling } \\
\text { pathway }\end{array}$ & 04020 & 16 & $\begin{array}{l}\text { ATP2B3, RYR1, NTSR1, NOS1, HTR5A, } \\
\text { SLC25A31, GNAS, DRD5, CACNA1C, } \\
\text { CALML5, P2RX6, ADCY9, CACNA1B, } \\
\text { CALML3, ADCY7, HRH1 }\end{array}$ & $\begin{array}{l}\mathrm{C}=177 ; \mathrm{O}=16 ; \mathrm{E}=6.54 ; \mathrm{R}=2.45 \\
\operatorname{raw} \mathrm{P}=0.0009 ; \operatorname{adj} \mathrm{P}=0.0140\end{array}$ \\
\hline $\begin{array}{l}\text { Pathogenic } \\
\text { Escherichia coli } \\
\text { infection }\end{array}$ & 05130 & 8 & $\begin{array}{l}\text { FYN, TUBA3C, ARPC1B, NCK2, ARPC2, } \\
\text { TUBB8, TUBA3E, TUBB3 }\end{array}$ & $\begin{array}{l}\mathrm{C}=56 ; \mathrm{O}=8 ; \mathrm{E}=2.07 ; \mathrm{R}=3.87 \\
\text { raw } \mathrm{P}=0.0010 ; \text { adj } \mathrm{P}=0.0140\end{array}$ \\
\hline $\begin{array}{l}\text { Chemokine } \\
\text { signaling } \\
\text { pathway }\end{array}$ & 04062 & 16 & $\begin{array}{l}\text { CXCR5, CX3CR1, BCAR1, TIAM2, SHC1, } \\
\text { GNGT2, ADCY5, ADCY9, IL8, ADCY6, GRK1, } \\
\text { ARRB2, TIAM1, PARD3, ADCY7, GRK7 }\end{array}$ & $\begin{array}{l}\mathrm{C}=189 ; \mathrm{O}=16 ; \mathrm{E}=6.99 ; \mathrm{R}=2.29 \\
\operatorname{raw} \mathrm{P}=0.0019 ; \operatorname{adj} \mathrm{P}=0.0169\end{array}$ \\
\hline Gap junction & 04540 & 10 & $\begin{array}{l}\text { GNAS, TUBA3C, ADCY5, ADCY9, GJD2, } \\
\text { ADCY6, TUBB8, TUBA3E, TUBB3, ADCY7 }\end{array}$ & $\begin{array}{l}\mathrm{C}=90 ; \mathrm{O}=10 ; \mathrm{E}=3.33 ; \mathrm{R}=3.01 \\
\operatorname{rawP}=0.0018 ; \operatorname{adj} \mathrm{P}=0.0169\end{array}$ \\
\hline Gastric acid secretion & 04971 & 9 & $\begin{array}{l}\text { GNAS, CALML5, ADCY5, ATP1A4, ADCY9, } \\
\text { ADCY6, ATP4B, CALML3, ADCY7 }\end{array}$ & $\begin{array}{l}\mathrm{C}=74 ; \mathrm{O}=9 ; \mathrm{E}=2.74 ; \mathrm{R}=3.29 \\
\operatorname{rawP}=0.0016 ; \operatorname{adj} \mathrm{P}=0.0169\end{array}$ \\
\hline Melanogenesis & 04916 & 10 & $\begin{array}{l}\text { GNAS, CALML5, ADCY5, FZD9, ADCY9, } \\
\text { POMC, ADCY6, CALML3, TCF7L2, ADCY7 }\end{array}$ & $\begin{array}{l}\mathrm{C}=101 ; \mathrm{O}=10 ; \mathrm{E}=3.73 ; \mathrm{R}=2.68 \\
\operatorname{rawP}=0.0042 ; \operatorname{adj} \mathrm{P}=0.0317\end{array}$ \\
\hline Pancreatic secretion & 04972 & 10 & $\begin{array}{l}\text { GNAS, CTRB1, CELA3A, ATP2B3, ADCY5, } \\
\text { PRSS3, ATP1A, ADCY9, ADCY6, ADCY7 }\end{array}$ & $\begin{array}{l}\mathrm{C}=101 ; \mathrm{O}=10 ; \mathrm{E}=3.73 ; \mathrm{R}=2.68 \\
\operatorname{rawP}=0.0042 ; \operatorname{adj} \mathrm{P}=0.0317\end{array}$ \\
\hline
\end{tabular}

$\mathrm{C}$, the number of reference genes in the category; $\mathrm{O}$ is the number of genes in the gene set and also in the category; $\mathrm{E}$, the expected number in the category; R, ratio of enrichment; rawP, P-value from hypergeometric test; adjP, P-value adjusted by the multiple test adjustment.

$\mathrm{P}=1.60 \mathrm{E}-02)$. The significant $\mathrm{GO}$ categories of these genes are shown in Fig. 6.

KEGG pathway analysis revealed that 5-hmC-CvP genes were enriched in 'MAPK signaling' (such as FGF4, FGF19, MEF2C and FGF3) and 'Pathway in cancer' (such as MMP9, SMAD4, FGF19 and FGF3), while 5-hmC-PvC genes were enriched in 'Cell cycle' (such as MDM2, STAG1 and E2F4) and 'Metabolic pathways' (such as ALG9, FLAD1, ST3GAL4, NDUFC2, POLR2J3, DHRS9 and G6PD). All significant pathways are listed in Table VI. The PANTHER classification system identified that DHMRs associated genes were mainly enriched in 'Nucleic acid binding' and 'Hydrolase', the same as the DMRs (Fig.5).

KEGG pathway analysis of 'metabolic pathway'-associated genes. There were several 5-mC and 5-hmC changed genes enriched in 'Metabolic pathways' further KEGG pathway analysis for these genes revealed that they were gathered in glucose metabolism [including 'Glycolysis/gluconeogenesis' (00010), 'Pentose and glucuronate interconversions' (00030), 'Starch and sucrose metabolism' (00500), 'Glycosaminoglycan degradation' (00531)], energy metabolism [including 'Oxidative phosphorylation' (00190), 'Citrate cycle (TCA cycle)' (00020), 'Carbon metabolism' (01200)], and amino acid metabolism, [including 'Biosynthesis of amino acids' (01230), 'Cysteine and methionine metabolism' (00270), 'Arginine and proline metabolism' (00330), ‘Arachidonic acid metabolism' (00590)] 'Purine metabolism' and 'Pyrimidine metabolism' (Fig. 7).

Both DMR and DHMR-associated genes. A total of 141 genes were found with both 5-mC and 5-hmC changes in at least two patients. KEGG pathway analysis for these 141 genes identified 

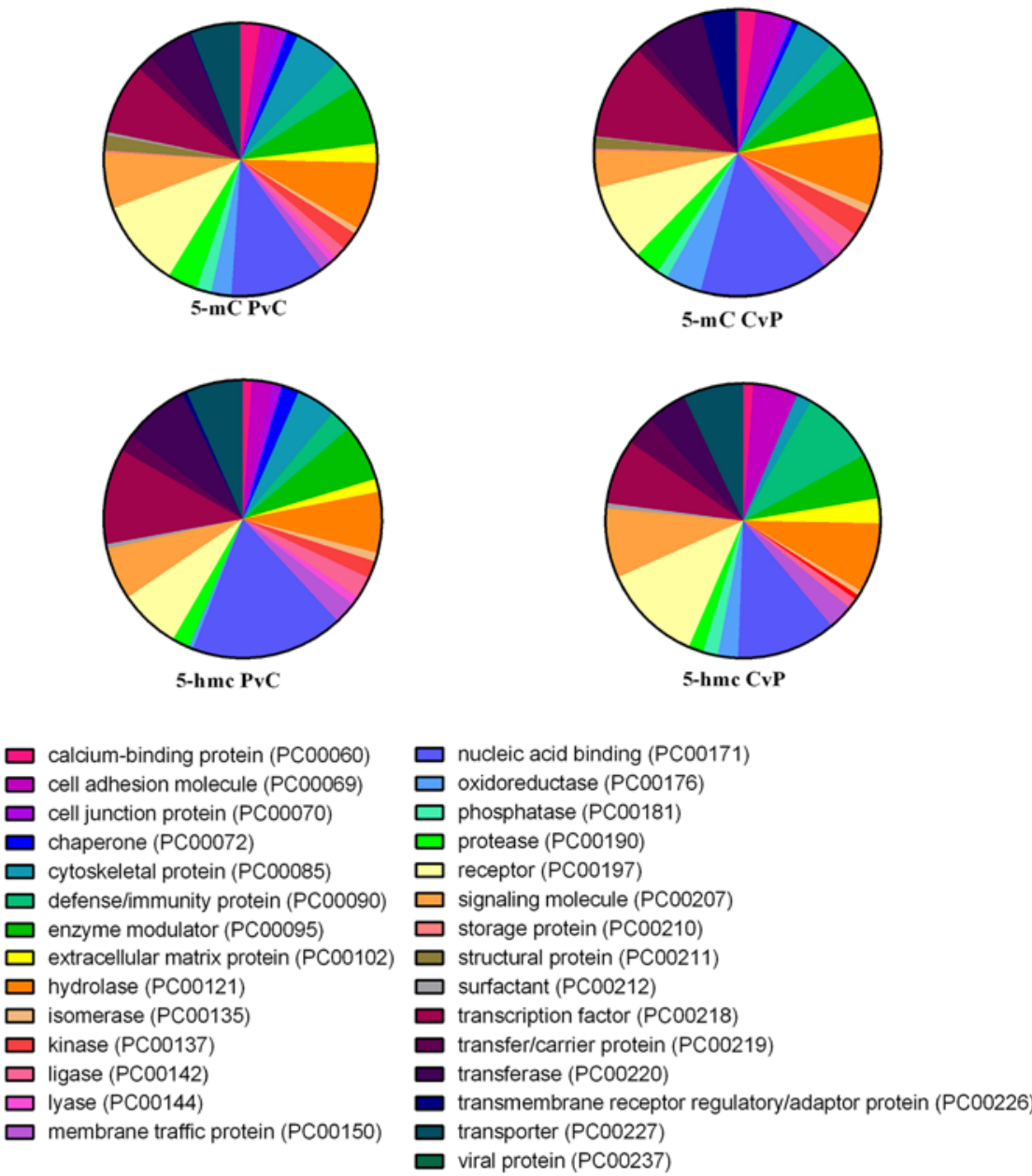

Figure 5. PANTHER protein class categories of hypermethylated (5-mC CvP)/hypomethylated (5-mC-PvC)/upregulated 5-hmC (5-hmC-CvP)/downregulated 5-hmC (5-hmC-PvC) genes in HCC tissues compared with APTs. (The chart legends show each detailed category).
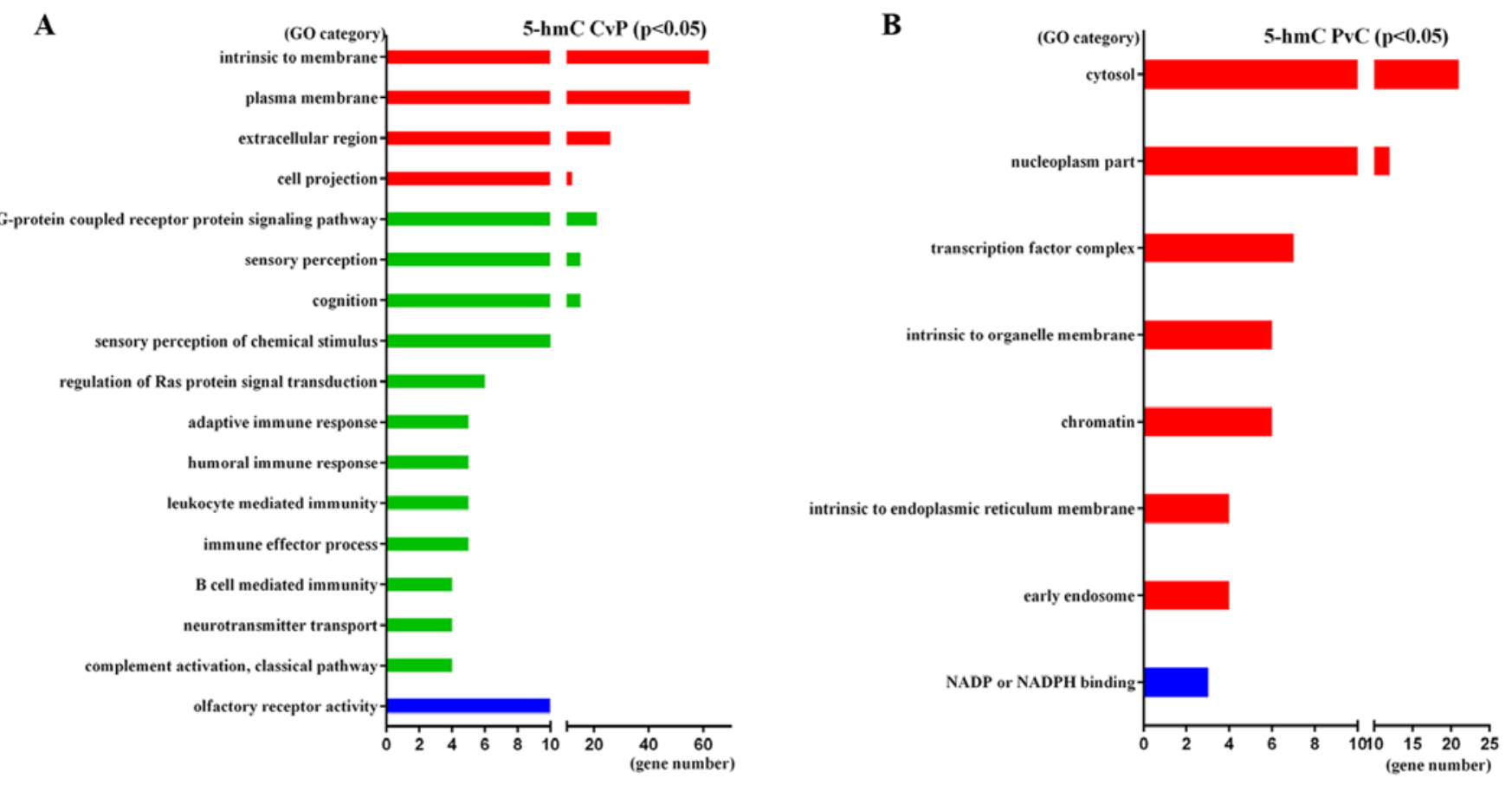

Figure 6. (A) The significant GO categories of upregulated 5-hmC genes (5-hmC-CvP) in HCC tissues compared with APTs (P<0.05). (B) The significant GO categories of downregulated 5-hmC genes $(5-\mathrm{hmC}-\mathrm{PvC})$ in $\mathrm{HCC}$ tissues compared with APTs $(\mathrm{P}<0.05)$ (Red, cellular component; green, biological process; blue, molecular function). 
Table VI. KEGG pathway analysis of upregulated and downregulated 5-hmC related genes.

A, KEGG pathway analysis of upregulated 5-hmC related genes

\begin{tabular}{|c|c|c|c|c|}
\hline Pathway name & ID & Gene & EntrezGene & Statistic \\
\hline Olfactory transduction & 04740 & 9 & $\begin{array}{l}\text { OR2T3, OR51V1, OR2L3, OR51F2, OR56A1 } \\
\text { OR2M3, OR52N5, OR4M2, OR4N4 }\end{array}$ & $\begin{array}{l}\mathrm{C}=388 ; \mathrm{O}=9 ; \mathrm{E}=1.65 ; \mathrm{R}=5.47 \\
\text { raw } \mathrm{P}=4.63 \mathrm{e}-05 ; \operatorname{adj} \mathrm{P}=0.0005\end{array}$ \\
\hline $\begin{array}{l}\text { Antigen processing } \\
\text { and presentation }\end{array}$ & 04612 & 3 & KIR3DL1, KIR3DL2, KIR3DL3 & $\begin{array}{l}\mathrm{C}=76 ; \mathrm{O}=3 ; \mathrm{E}=0.32 ; \mathrm{R}=9.30 \\
\operatorname{raw} \mathrm{P}=0.0042 ; \operatorname{adj} \mathrm{P}=0.0092\end{array}$ \\
\hline Melanoma & 05218 & 3 & FGF4, FGF19, FGF3 & $\begin{array}{l}\mathrm{C}=71 ; \mathrm{O}=3 ; \mathrm{E}=0.30 ; \mathrm{R}=9.96 \\
\operatorname{raw} \mathrm{P}=0.0035 ; \operatorname{adj} \mathrm{P}=0.0092\end{array}$ \\
\hline $\begin{array}{l}\text { Natural killer cell } \\
\text { mediated cytotoxicity }\end{array}$ & 04650 & 4 & KIR3DL1, ICAM2, KIR3DL2, KIR3DL3 & $\begin{array}{c}\mathrm{C}=136 ; \mathrm{O}=4 ; \mathrm{E}=0.58 ; \mathrm{R}=6.93 \\
\operatorname{raw} \mathrm{P}=0.0028 ; \operatorname{adj} \mathrm{P}=0.0092\end{array}$ \\
\hline Pathways in cancer & 05200 & 5 & MMP9, FGF4, SMAD4, FGF19, FGF3 & $\begin{array}{c}\mathrm{C}=326 ; \mathrm{O}=5 ; \mathrm{E}=1.38 ; \mathrm{R}=3.61 \\
\operatorname{raw} \mathrm{P}=0.0130 ; \operatorname{adj} \mathrm{P}=0.0238\end{array}$ \\
\hline MAPK signaling pathway & 04010 & 4 & FGF4, FGF19, MEF2C, FGF3 & $\begin{array}{c}\mathrm{C}=268 ; \mathrm{O}=4 ; \mathrm{E}=1.14 ; \mathrm{R}=3.52 ; \\
\operatorname{rawP}=0.0278 ; \operatorname{adj} \mathrm{P}=0.0382\end{array}$ \\
\hline RNA transport & 03013 & 3 & NUP62, GEMIN4, NXT2 & $\begin{array}{c}\mathrm{C}=151 ; \mathrm{O}=3 ; \mathrm{E}=0.64 ; \mathrm{R}=4.68 \\
\operatorname{rawP}=0.0268 ; \operatorname{adj} \mathrm{P}=0.0382\end{array}$ \\
\hline
\end{tabular}

B, KEGG pathway analysis of downregulated 5-hmC related genes

\begin{tabular}{|c|c|c|c|c|}
\hline Pathway name & ID & Gene & EntrezGene & Statistics \\
\hline Cell cycle & 04110 & 5 & MDM2, STAG1, E2F4, CDK4, TFDP1 & $\begin{array}{l}\mathrm{C}=124 ; \mathrm{O}=5 ; \mathrm{E}=0.78 ; \mathrm{R}=6.37 \\
\operatorname{rawP}=0.0012 ; \mathrm{adj} \mathrm{P}=0.0140\end{array}$ \\
\hline TGF- $\beta$ signaling pathway & 04350 & 4 & DCN, GDF6, E2F4, TFDP1 & $\begin{array}{l}\mathrm{C}=84 ; \mathrm{O}=4 ; \mathrm{E}=0.53 ; \mathrm{R}=7.52 ; \\
\text { raw } \mathrm{P}=0.0020 ; \mathrm{adj} \mathrm{P}=0.0140\end{array}$ \\
\hline $\begin{array}{l}\text { Staphylococcus aureus } \\
\text { infection }\end{array}$ & 05150 & 3 & C1QB, FCGR3B, C3AR1 & $\begin{array}{l}\mathrm{C}=55 ; \mathrm{O}=3 ; \mathrm{E}=0.35 ; \mathrm{R}=8.62 ; \\
\text { raw } \mathrm{P}=0.0052 ; \mathrm{adj} \mathrm{P}=0.0243\end{array}$ \\
\hline $\begin{array}{l}\text { Epithelial cell signaling } \\
\text { in Helicobacter pylori } \\
\text { infection }\end{array}$ & 05120 & 3 & F11R, ATP6V1G2, ATP6V0A4 & $\begin{array}{l}\mathrm{C}=68 ; \mathrm{O}=3 ; \mathrm{E}=0.43 ; \mathrm{R}=6.97 \\
\operatorname{raw} \mathrm{P}=0.0093 ; \mathrm{adj} \mathrm{P}=0.0254\end{array}$ \\
\hline $\begin{array}{l}\text { Ubiquitin mediated } \\
\text { proteolysis }\end{array}$ & 04120 & 4 & RHOBTB2, UBE2Q1, UBE3B, MDM2 & $\begin{array}{l}\mathrm{C}=135 ; \mathrm{O}=4 ; \mathrm{E}=0.85 ; \mathrm{R}=4.68 \\
\text { raw } \mathrm{P}=0.0109 ; \operatorname{adj} \mathrm{P}=0.0254\end{array}$ \\
\hline $\begin{array}{l}\text { Protein processing in } \\
\text { endoplasmic reticulum }\end{array}$ & 04141 & 4 & HSP90AA1, ERP29, DNAJA2, TXNDC5 & $\begin{array}{l}\mathrm{C}=165 ; \mathrm{O}=4 ; \mathrm{E}=1.04 ; \mathrm{R}=3.83 \\
\operatorname{rawP}=0.0212 ; \operatorname{adj} \mathrm{P}=0.0371\end{array}$ \\
\hline Metabolic pathways & 01100 & 13 & $\begin{array}{l}\text { ALG9, FLAD1, ST3GAL4, NDUFC2, } \\
\text { POLR2J3, DHRS9, G6PD, ATP6V1G2, } \\
\text { SMPD1, ASMT, ATP6V0A4, NOS1, AKR1A1 }\end{array}$ & $\begin{array}{l}\mathrm{C}=1130 ; \mathrm{O}=13 ; \mathrm{E}=7.15 ; \mathrm{R}=1.82 ; \\
\operatorname{raw} \mathrm{P}=0.0290 ; \operatorname{adj} \mathrm{P}=0.0451\end{array}$ \\
\hline
\end{tabular}

$\mathrm{C}$, the number of reference genes in the category; $\mathrm{O}$, the number of genes in the gene set and also in the category; E, the expected number in the category; R, ratio of enrichment; rawP, P-value from hypergeometric test; adjP, P-value adjusted by the multiple test adjustment.

five major pathways involved ('Cell cycle', 'Pathway in cancer', 'Ubiquitin mediated proteolysis', 'Melanoma' and 'Prostate cancer') were enriched (adjp<0.05). Ten interconnected and enriched genes (PCNA, MDM2, STAG1, E2F4, FGF4, FGF19, RHOBTB2, UBE2QL1, DCN and HSP90AA1) were revealed (Fig. 8).

\section{Discussion}

DNA methylation is one of the major epigenetic mechanisms that regulate gene expression in humans, and the alterations of methylation profiles are regarded as one of the major molecular aberrations in malignancies $(23,24)$. Several 


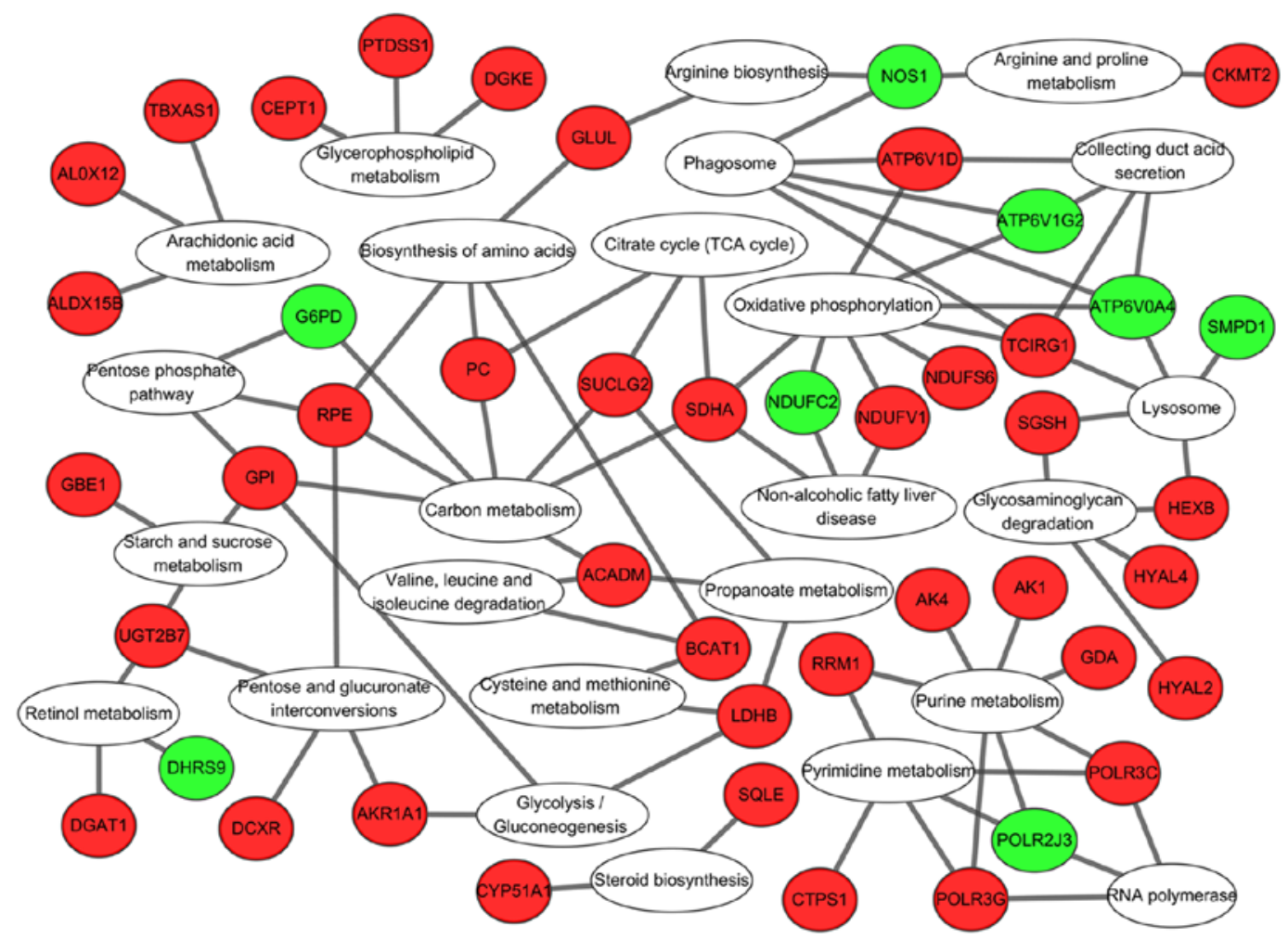

Figure 7. KEGG pathway analysis of 'Metabolic pathway' involved genes (Red, 5-mC changed genes; green, 5-hmC changed genes; white, KEGG pathways).

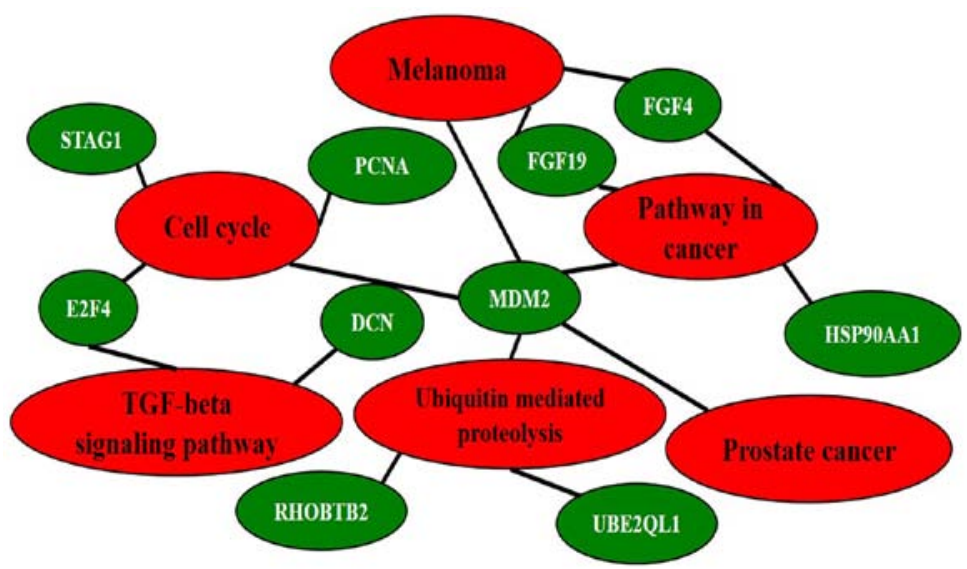

Figure 8. KEGG pathway analysis of both 5-mC and 5-hmC changed genes. (adjp<0.05) (adjp, P-value adjusted by the multiple test adjustment; red, KEGG pathways; green, genes).

studies of genome-wide DNA methylation have shown that the characteristic features of CpGs and certain microRNAs had differences in methylation levels between HCC and noncancerous livers $(25,26)$. Thus far, only a few studies have reported that DNA hydroxymethylation is associated with several human cancers $(14,27)$, yet, the biological significance of 5-hmC in tumorigenesis remains unclear. In the present study we showed widespread alterations in DNA methylation and hydroxymethylation in HCC tumor tissues and paired APTs. 5-mC and 5-hmC levels exhibited no significant differences between the groups, which might be due to the huge variation between HCC individuals. The strong features of this study include the highly sensitive method and high-throughput sequencing used, which enabled the non-biased mapping of aberrant (hydroxy) methylation sites between the tumor tissues and APTs, and distinguished the alternation of 5-mC from that of 5-hmC. To the best of our knowledge, this is the first report on the genome-wide profiling of 5-mC and 5-hmC in HCC using this technique.

As is known, in the mammalian genome, methylation takes place only at cytosine bases that are located $5^{\prime}$ to a guanosine in a CpG dinucleotide, known as $\mathrm{CpG}$ islands. Most $\mathrm{CpG}$ islands are found in the proximal promoter regions (28). Methylation and demethylation in promoter region may regulate gene expression, playing important roles in biology process, especially in the development of tumors $(25,29,30)$. The 
identification of genes that are specifically hypermethylated (which results in gene silencing) or hypomethylated (which results in increased transcription) might lead to the discovery of new factors that are important for tumor initiation and progression. In this study, we identified 1133 hypermethylated genes and 1663 hypomethylated genes in the promoter regions, many more than reported in a previous study (19), proving that MeDIP-seq has a better sensitivity than microarray, and more methylated sites can be found by using this novel technology. GO analysis showed they were enriched in various biological processes. Hypermethylation mostly gathered in 'Regulation'-related biology processes, including 'Regulation of RNA metabolic process' $(\mathrm{P}=4.10 \mathrm{E}-05)$, 'Regulation of kinase activity' $(\mathrm{P}=8.80 \mathrm{E}-03)$ and 'Regulation of transcription' ( $\mathrm{P}=9.40 \mathrm{E}-04)$. Although it is widely accepted that 'DNA methylation suppresses gene expression', this statement is an over-simplification. Methylation at the promoter regions can change the interactions between proteins and DNA, which can lead to the alterations in chromatin structure and either a decrease or an increase in the rate of transcription $(31,32)$. We indeed found hypermethylation genes en riched in 'protein-DNA complex assembly' ( $\mathrm{P}=9.40 \mathrm{E}-03)$. Furthermore, the position of the methylation change relative to the transcription start site is critical to the outcome (23). 'Binding' is another category where the hypermethylated genes are enriched, and it includes 'DNA binding' ( $\mathrm{P}=4.60 \mathrm{E}-05)$, 'Ion binding' $(\mathrm{P}=1.20 \mathrm{E}-03)$ and 'RNA binding' ( $\mathrm{P}=3.60 \mathrm{E}-02)$, which are accordant with the results of Zhai et al (33) In contrast, hypomethylation genes are enriched in totally different categories, such as 'Plasma membrane' $(\mathrm{p}=2.80 \mathrm{E}-05)$, 'Cytoskeleton' $(\mathrm{P}=9.70 \mathrm{E}-03)$ and ' $\mathrm{G}$-protein coupled receptor protein signaling pathway' $(\mathrm{P}=4.60 \mathrm{E}-03)$.

Our KEGG pathway analysis identified some interesting pathways for hypermethylation. 'Pathway in cancer' contained genes such as CDKN2A and CDKN2B (cyclin-dependent kinase inhibitor $2 \mathrm{~A} / 2 \mathrm{~B}$ ) that are recognized as a tumor suppressor genes. The inactivation of CDKN2A/2B have been reported in several primary tumors (34-36). There might be three different molecular mechanisms resulting in the loss of the CDKN2A/2B gene functions, namely homozygous deletions, point mutations, and transcriptional silencing by methylation at $\mathrm{CpG}$ islands. Methylation of CDKN2 has been observed in cell lines and cancer specimens derived from glioma, breast, colonic, head and neck cancers, hepatoblastoma, and in transitional cell carcinomas of the bladder (37-39). Shen et al (40) used Illumina Methylated Arrays and pyrosequencing technique and indicated that CDKN2A may be a potential biomarker for early HCC diagnosis. Another important gene in this pathway is APC (adenomatous polyposis coli) which also is an important tumor associated gene. The profiling of gene promoter hypermethylation across human tumor types showed that APC promoter hypermethylation occurred in tumors including colon, breast, kidney, bladder, esophagus, stomach, pancreas and liver tumors (41). Furthermore, studies showed that high-level APC promoter methylation is a useful biomarker and predictor in esophageal adenocarcinoma, breast and prostate cancer (42-44). Methylation of APC in $\mathrm{HCC}$ is frequent and occurs in a gene-specific and diseasespecific manner. It was detected more frequently in hepatitis C virus-positive HCC $(45,46)$. Other genes such as GSTP1
(Glutathione S-transferase P1) have also been found to be epigenetically silenced by promoter methylation, and associated with increased risk and shortened survival in patients with various tumors, including $\mathrm{HCC}$, breast and prostate cancer (47-49). Promoter methylation and epigenetic silencing of DAPK3 (death-associated protein kinase 3) and FADD [Fas (TNFRSF6)-associated via death domain] have not been studied in depth to the extent of those genes, and only a few studies implicated their participation in cancers such as oral squamous cell carcinoma and non-muscle invasive bladder carcinoma (50-52). Their promoter methylation could also be a potential marker for HCC, and further studies are needed to confirm this. Other identified pathways such as 'Cell cycle' (PCNA, STAG1, YWHAZ, ORC1, TFDP2 and CDC23) and 'Chemokine signaling pathway' (GNG12, NRAS, ELMO1, PIK3R5, ADCY5, PRKCZ and PLCB4) are also considered to be important for the development and progression of malignant carcinoma, and the involved genes with their methylation status may provide potential novel biomarkers for HCC.

5 -hmC is usually found in human embryonic stem (ES) cells and particularly abundant in certain genomic regions such as enhancers associated with histone modifications and other protein-DNA interaction sites based both on the information of gene expression and sequence composition (53). However, in human HCC tumor tissues and paired APTs, the locations of DHMRs seemed not to be significantly different among the whole genomic region. Although there is substantial evidence indicating that hydroxymethylation may be associated with actively transcribed genes, the exact biochemical mechanisms still remain enigmatic $(54,55)$. Our GO analysis showed that compared with APTs, both highlevel hydroxymethylated genes and hypomethylated genes in HCC tissues were enriched in the same pathways, namely the 'Plasma membrane' $(\mathrm{P}=3.10 \mathrm{E}-05)$ and 'G-protein coupled receptor protein signaling pathway' $(\mathrm{P}=3.60 \mathrm{E}-03)$, indicating that hydroxymethylation as a kind of demethylation may play similar or related roles with hypomethylation. In contrast, the downregulated hydroxymethylated genes are found mainly gathered in the 'Cytosol' ( $\mathrm{P}=3.10 \mathrm{E}-02)$.

Although the KEGG pathway analysis for 5-hmC did not come up with as many enriched genes as that for 5-mC, they can still be categorized into a number of meaningful pathways. For instance, high level hydroxymethylated genes such as MMP9, SMAD4, FGF19, FGF3 and MEF2C were enriched in 'Pathway in cancer' and 'MAPK signaling pathway', while low level hydroxymethylated genes were mostly enriched in 'Metabolic pathways' and 'Cell cycle'. 'TGF- $\beta$ signaling pathway' related genes DCN, E2F4, TFDP1 also have strong correlations with tumors (56-58). Since there have been few studies on the hydroxymethylation of these genes, more work is needed to fully elucidate the potential roles of hydroxymethylation. Protein class analysis by PANTHER website showed that both DMR and DHMR-associated genes were in similar category, indicating that genes with hypermethylation or demethylation epigenetic changes tend to be coordinately regulated to participate in similar or related biology processes. Further work is warranted to test this hypothesis.

Over half a century ago, Warburg linked metabolism and cancer through enhanced aerobic glycolysis (59). This metabolic switch places the emphasis on producing intermediates 
for cell growth and division. The most rapidly growing tumor cell lines obtain up to $50 \%$ of their total ATP production from glycolytic metabolism, with a corresponding decrease in oxidative phosphorylation and in cell mitochondrial content $(60,61)$. With numerous in-depth studies, the multifaceted links between metabolism and cancer have now been revealed. Cellular metabolism is regulated by both oncogenes and tumor suppressor genes in a number of key signaling pathways. Metabolism generates oxygen radicals, which contribute to oncogenic mutations. Activated oncogenes and loss of tumor suppressors in turn alter metabolism and induce aerobics (62). In the present study, we found several 5-mC and 5-hmC changed genes enriched in 'Metabolic pathways', and further analysis showed they were specifically clustered in 'Glycolysis/gluconeogenesis', 'Oxidative phosphorylation' and 'Citrate cycle (TCA cycle)' (Fig. 7), metabolic pathways were proven to be critical in controlling cancer cell survival and proliferation. Although the regulatory mechanisms underlying aerobic and glycolytic metabolic pathways are complex, our findings indicate that (hydroxy)methylation-based epigenetic modifications may affect the development of HCC through the regulation of cellular metabolism.

DNA methylation as a characterized epigenetic mechanism, its relationship with other biochemical pathways represents a critical stage in the elucidation of biological information processing. Some amino acid metabolism has been related to DNA methylation in tumors, such as homocysteine metabolism and the dynamics of methionine cycle $(63,64)$. Accordingly, this study also found several $5-\mathrm{mC}$ and 5 -hmC changed genes that are associated with amino acid metabolism, including 'Arginine biosynthesis', 'Cysteine and methionine metabolism', 'Valine, leucine and isoleucine degradation' and 'Arginine and proline metabolism' which may provide new clues for studying the relationship between (hydroxy)methylation and metabolism in HCC.

The present study found that a total of 141 genes have both 5-mC and 5-hmC changes in at least two of the HCC patients. KEGG pathway analysis showed five pathways ('Cell cycle', 'Pathway in cancer', 'Ubiquitin mediated proteolysis', 'Melanoma' and 'Prostate cancer') including ten genes (PCNA, MDM2, SAG1, E2F4, FGF4, FGF19, RHOBTB2, UBE2QL1, DCN and HSP90AA1) are enriched (Fig. 8). It is known for decades that, PCNA (proliferating cell nuclear antigen) acts as a central coordinator of DNA transactions by providing a multivalent interaction surface for factors involved in DNA replication, repair, chromatin dynamics, and cell cycle regulation (65), and is involved in the progression of tumors and highly altered in some tumors (66). Furthermore, studies have shown that the $\mathrm{p} 21$ protein negatively regulates targeting of DNA-MTase to the replication associated PCNA. They proposed that the presence of p21 prevents DNA-MTase access to replicating DNA, thereby impeding hypermethylation in normal cells (67). The present study indicated that (hydroxy) methylation of PCNA might be associated with HCC, which warrants further study. The 90-kDa heat shock protein HSP90AA1, another p21 regulator, has been found highly expressed in many cancers. Its mechanism in the tumorigenesis is varied $(68,69)$. Here we provided evidence that methylation or hydroxymethylation of HSP90AA1 may play a crucial role in HCC. The epigenetic alterations of other identified genes such as MDM2, SAG, FGF4, FGF19, RHOBTB2 and DCN in HCC and other cancers also deserve further research.

One of the potential limitations of the present study is the sample size, which may not be sufficiently large. This is mainly due to the high cost of (h)MeDIP-seq, which precludes its application in a large scale. Nevertheless, we performed a rather comprehensive methylation and hydroxymethylation profiling of human HCC tumor tissues and paired APTs, and correlated multiple (hydroxy)methylation-altered genes with a number of important biological pathways. 'Metabolic pathways' are found to contain the largest number of (hydroxy) methylation-altered genes, indicating the crucial roles of metabolic processes (such as glycolysis/gluconeogenesis, oxidative phosphorylation and citrate cycle) in the occurrence and progression of HCC. Some of the identified (hydroxy) methylation-altered genes may serve as biomarkers for the diagnosis and prognosis of HCC. Future studies with a larger sample size combined with a series of biochemical approaches hold the promise of elucidating the specific roles of epigenetic modifications in the pathogenesis of HCC.

\section{Acknowledgements}

We thank Professor Yingjie Wang for the helpful comments and language supports on this manuscript. The present study is supported by the Chinese High Tech Research and Development (863) Program (grant nos. 2012AA020204 and 2013AA020102) and the National S\&T Major Project (grant no. 2012ZZX10002004-001).

\section{References}

1. Bertino G, Demma S, Ardiri A, Proiti M, Gruttadauria S, Toro A, Malaguarnera G, Bertino N, Malaguarnera M, Malaguarnera M, et al: Hepatocellular carcinoma: Novel molecular targets in carcinogenesis for future therapies. BioMed Res Int 2014: 203693, 2014

2. Ishikawa T: Clinical features of hepatitis B virus-related hepatocellular carcinoma. World J Gastroenterol 16: 2463-2467, 2010.

3. Bréchot C, Gozuacik D, Murakami Y and Paterlini-Bréchot P: Molecular bases for the development of hepatitis B virus (HBV)related hepatocellular carcinoma (HCC). Semin Cancer Biol 10: 211-231, 2000.

4. Ma S, Jiao B, Liu X, Yi H, Kong D, Gao L, Zhao G, Yang Y and Liu X: Approach to radiation therapy in hepatocellular carcinoma. Cancer Treat Rev 36: 157-163, 2010.

5. Lo CM, Ngan H, Tso WK, Liu CL, Lam CM, Poon RT, Fan ST and Wong J: Randomized controlled trial of transarterial lipiodol chemoembolization for unresectable hepatocellular carcinoma. Hepatology 35: 1164-1171, 2002.

6. Poon RT, Fan ST, Lo CM, Ng IO, Liu CL, Lam CM and Wong J: Improving survival results after resection of hepatocellular carcinoma: A prospective study of 377 patients over 10 years. Ann Surg 234: 63-70, 2001.

7. Jones PA and Baylin SB: The epigenomics of cancer. Cell 128: 683-692, 2007

8. Paska AV and Hudler P: Aberrant methylation patterns in cancer: A clinical view. Biochem Med Zagreb 25: 161-176, 2015.

9. Robertson KD: DNA methylation and human disease. Nat Rev Genet 6: 597-610, 2005.

10. Globisch D, Münzel M, Müller M, Michalakis S, Wagner M, Koch S, Brückl T, Biel M and Carell T: Tissue distribution of 5-hydroxymethylcytosine and search for active demethylation intermediates. PLoS One 5: e15367, 2010.

11. Ruzov A, Tsenkina Y, Serio A, Dudnakova T, Fletcher J, Bai Y, Chebotareva T, Pells S, Hannoun Z, Sullivan G, et al: Lineage-specific distribution of high levels of genomic 5-hydroxymethylcytosine in mammalian development. Cell Res 21: $1332-1342,2011$. 
12. Tan L and Shi YG: Tet family proteins and 5-hydroxymethylcytosine in development and disease. Development 139: 1895-1902, 2012.

13. Branco MR, Ficz G and Reik W: Uncovering the role of 5-hydroxymethylcytosine in the epigenome. Nat Rev Genet 13 7-13, 2011.

14. Haffner MC, Chaux A, Meeker AK, Esopi DM, Gerber J, Pellakuru LG, Toubaji A, Argani P, Iacobuzio-Donahue C, Nelson WG, et al: Global 5-hydroxymethylcytosine content is significantly reduced in tissue stem/progenitor cell compartments and in human cancers. Oncotarget 2: 627-637, 2011.

15. Moribe T, Iizuka N, Miura T, Kimura N, Tamatsukuri S, Ishitsuka H, Hamamoto Y, Sakamoto K, Tamesa T and Oka M: Methylation of multiple genes as molecular markers for diagnosis of a small, well-differentiated hepatocellular carcinoma. Int J Cancer 125: 388-397, 2009.

16. Lou C, Du Z, Yang B, Gao Y, Wang Y and Fang S: Aberrant DNA methylation profile of hepatocellular carcinoma and surgically resected margin. Cancer Sci 100: 996-1004, 2009.

17. Mardis ER: Next-generation DNA sequencing methods. Annu Rev Genomics Hum Genet 9: 387-402, 2008.

18. Shendure J and Ji H: Next-generation DNA sequencing. Nat Biotechnol 26: 1135-1145, 2008.

19. Shitani M, Sasaki S, Akutsu N, Takagi H, Suzuki H, Nojima M, Yamamoto H, Tokino T, Hirata K, Imai K, et al: Genome-wide analysis of DNA methylation identifies novel cancer-related genes in hepatocellular carcinoma. Tumour Biol 33: 1307-1317, 2012.

20. Shen J, Wang S, Zhang YJ, Wu HC, Kibriya MG, Jasmine F, Ahsan H, Wu DP, Siegel AB, Remotti H, et al: Exploring genome-wide DNA methylation profiles altered in hepatocellular carcinoma using Infinium HumanMethylation 450 BeadChips. Epigenetics 8: 34-43, 2013.

21. Iyer P, Zekri AR, Hung CW, Schiefelbein E, Ismail K, Hablas A, Seifeldin IA and Soliman AS: Concordance of DNA methylation pattern in plasma and tumor DNA of Egyptian hepatocellular carcinoma patients. Exp Mol Pathol 88: 107-111, 2010.

22. Tan L, Xiong L, Xu W, Wu F, Huang N, Xu Y, Kong L, Zheng L, Schwartz L, Shi Y, et al: Genome-wide comparison of DNA hydroxymethylation in mouse embryonic stem cells and neural progenitor cells by a new comparative hMeDIP-seq method. Nucleic Acids Res 41: e84, 2013.

23. Jones PA and Takai D: The role of DNA methylation in mammalian epigenetics. Science 293: 1068-1070, 2001

24. Esteller M: Epigenetics in cancer. N Engl J Med 358: 1148-1159, 2008.

25. Shen J, Wang S, Zhang YJ, Kappil MA, Chen Wu H, Kibriya MG, Wang Q, Jasmine F, Ahsan H, Lee PH, et al: Genome-wide aberrant DNA methylation of microRNA host genes in hepatocellular carcinoma. Epigenetics 7: 1230-1237, 2012.

26. Nishida N, Nishimura T, Nakai T, Chishina H, Arizumi T, Takita M, Kitai S, Yada N, Hagiwara S, Inoue T, et al: Genomewide profiling of DNA methylation and tumor progression in human hepatocellular carcinoma. Dig Dis 32: 658-663, 2014.

27. Kudo Y, Tateishi K, Yamamoto K, Yamamoto S, Asaoka Y, Ijichi H, Nagae G, Yoshida H, Aburatani H and Koike K: Loss of 5-hydroxymethylcytosine is accompanied with malignant cellular transformation. Cancer Sci 103: 670-676, 2012.

28. Bird A: DNA methylation patterns and epigenetic memory Genes Dev 16: 6-21, 2002.

29. Jones PA and Laird PW: Cancer epigenetics comes of age. Nat Genet 21: 163-167, 1999.

30. Jones PA and Baylin SB: The fundamental role of epigenetic events in cancer. Nat Rev Genet 3: 415-428, 2002.

31. Jones PL, Veenstra GJ, Wade PA, Vermaak D, Kass SU, Landsberger N, Strouboulis J and Wolffe AP: Methylated DNA and $\mathrm{MeCP} 2$ recruit histone deacetylase to repress transcription. Nat Genet 19: 187-191, 1998

32. Gonzalgo ML, Hayashida T, Bender CM, Pao MM, Tsai YC, Gonzales FA, Nguyen HD, Nguyen TT and Jones PA: The role of DNA methylation in expression of the p19/p16 locus in human bladder cancer cell lines. Cancer Res 58: 1245-1252, 1998.

33. Zhai JM, Yin XY, Hou X, Hao XY, Cai JP, Liang LJ and Zhang LJ: Analysis of the genome-wide DNA methylation profile of side population cells in hepatocellular carcinoma. Dig Dis Sci 58: 1934-1947, 2013

34. Cairns P, Mao L, Merlo A, Lee DJ, Schwab D, Eby Y, Tokino K, van der Riet P, Blaugrund JE and Sidransky D: Rates of p16 (MTS1) mutations in primary tumors with $9 \mathrm{p}$ loss. Science 265 : 415-417, 1994
35. Okamoto A, Demetrick DJ, Spillare EA, Hagiwara K, Hussain SP, Bennett WP, Forrester K, Gerwin B, Serrano M and Beach DH: Mutations and altered expression of p16INK4 in human cancer. Proc Natl Acad Sci USA 91: 11045-11049, 1994.

36. Rousseau E, Ruchoux MM, Scaravilli F, Chapon F, Vinchon M, De Smet C, Godfraind C and Vikkula M: CDKN2A, CDKN2B and p14ARF are frequently and differentially methylated in ependymal tumours. Neuropathol Appl Neurobiol 29: 574-583, 2003.

37. Gonzalez-Zulueta M, Bender CM, Yang AS, Nguyen T, Beart RW, Van Tornout JM and Jones PA: Methylation of the 5 $\mathrm{CpG}$ island of the p16/CDKN2 tumor suppressor gene in normal and transformed human tissues correlates with gene silencing. Cancer Res 55: 4531-4535, 1995.

38. Colot V and Rossignol JL: Isolation of the Ascobolus immersus spore color gene b2 and study in single cells of gene silencing by methylation induced premeiotically. Genetics 141: 1299-1314, 1995.

39. Iolascon A, Giordani L, Moretti A, Basso G, Borriello A and Della Ragione F: Analysis of CDKN2A, CDKN2B, CDKN2C and cyclin Ds gene status in hepatoblastoma. Hepatology 27: 989-995, 1998

40. Shen J, Wang S, Zhang YJ, Kappil M, Wu HC, Kibriya MG, Wang Q, Jasmine F, Ahsan H, Lee PH, et al: Genome-wide DNA methylation profiles in hepatocellular carcinoma. Hepatology 55: 1799-1808, 2012

41. Esteller M, Corn PG, Baylin SB and Herman JG: A gene hypermethylation profile of human cancer. Cancer Res 61: 3225-3229, 2001 .

42. Kawakami K, Brabender J, Lord RV, Groshen S, Greenwald BD, Krasna MJ, Yin J, Fleisher AS, Abraham JM, Beer DG, et al: Hypermethylated APC DNA in plasma and prognosis of patients with esophageal adenocarcinoma. J Natl Cancer Inst 92. 1805-1811, 2000

43. Van De Voorde L, Speeckaert R, Van Gestel D, Bracke M, De Neve W, Delanghe J and Speeckaert M: DNA methylationbased biomarkers in serum of patients with breast cancer. Mutat Res 751: 304-325, 2012.

44. Henrique R, Ribeiro FR, Fonseca D, Hoque MO, Carvalho AL, Costa VL, Pinto M, Oliveira J, Teixeira MR, Sidransky D, et al: High promoter methylation levels of APC predict poor prognosis in sextant biopsies from prostate cancer patients. Clin Cancer Res 13: 6122-6129, 2007.

45. Nishida N, Nagasaka T, Nishimura T, Ikai I, Boland CR and Goel A: Aberrant methylation of multiple tumor suppressor genes in aging liver, chronic hepatitis, and hepatocellular carcinoma. Hepatology 47: 908-918, 2008.

46. Yang B, Guo M, Herman JG and Clark DP: Aberrant promoter methylation profiles of tumor suppressor genes in hepatocellular carcinoma. Am J Pathol 163: 1101-1107, 2003.

47. Fang C, Wei XM, Zeng XT, Wang FB, Weng H and Long X: Aberrant GSTP1 promoter methylation is associated with increased risk and advanced stage of breast cancer: A metaanalysis of 19 case-control studies. BMC Cancer 15: 920, 2015.

48. Zelic R, Fiano V, Zugna D, Grasso C, Delsedime L, Daniele L, Galliano D, Pettersson A, Gillio-Tos A, Merletti F, et al: Global hypomethylation (LINE-1) and gene-specific hypermethylation (GSTP1) on initial negative prostate biopsy as markers of prostate cancer on a rebiopsy. Clin Cancer Res 22: 984-992, 2015.

49. Liu D, Wu J, Liu M, Yin H, He J and Zhang B: Downregulation of miRNA-30c and miR-203a is associated with hepatitis C virus core protein-induced epithelial-mesenchymal transition in normal hepatocytes and hepatocellular carcinoma cells. Biochem Biophys Res Commun 464: 1215-1221, 2015.

50. Saberi E, Kordi-Tamandani DM, Jamali S and Rigi-Ladiz MA: Analysis of methylation and mRNA expression status of FADD and FAS genes in patients with oral squamous cell carcinoma Med Oral Patol Oral Cir Bucal 19: e562-e568, 2014.

51. Friedrich MG, Chandrasoma S, Siegmund KD, Weisenberger DJ, Cheng JC, Toma MI, Huland H, Jones PA and Liang G: Prognostic relevance of methylation markers in patients with non-muscle invasive bladder carcinoma. Eur J Cancer 41: 2769-2778, 2005.

52. Brognard J, Zhang YW, Puto LA and Hunter T: Cancerassociated loss-of-function mutations implicate DAPK3 as a tumor-suppressing kinase. Cancer Res 71: 3152-3161, 2011.

53. Stroud H, Feng S, Morey Kinney S, Pradhan S and Jacobsen SE: 5-Hydroxymethylcytosine is associated with enhancers and gene bodies in human embryonic stem cells. Genome Biol 12: R54, 2011. 
54. Ficz G, Branco MR, Seisenberger S, Santos F, Krueger F, Hore TA, Marques CJ, Andrews S and Reik W: Dynamic regulation of 5-hydroxymethylcytosine in mouse ES cells and during differentiation. Nature 473: 398-402, 2011.

55. Ito S, D'Alessio AC, Taranova OV, Hong K, Sowers LC and Zhang Y: Role of Tet proteins in $5 \mathrm{mC}$ to $5 \mathrm{hmC}$ conversion, ES-cell self-renewal and inner cell mass specification. Nature 466: 1129-1133, 2010

56. Mlakar V, Berginc G, Volavsek M, Stor Z, Rems M and Glavac D: Presence of activating KRAS mutations correlates significantly with expression of tumour suppressor genes DCN and TPM1 in colorectal cancer. BMC Cancer 9: 282, 2009.

57. Nevins JR: The Rb/E2F pathway and cancer. Hum Mol Genet 10: 699-703, 2001.

58. Yasui K, Okamoto H, Arii S and Inazawa J: Association of overexpressed TFDP1 with progression of hepatocellular carcinomas. J Hum Genet 48: 609-613, 2003.

59. Warburg O: On the origin of cancer cells. Science 123: 309-314, 1956.

60. Pedersen PL: Tumor mitochondria and the bioenergetics of cancer cells. Prog Exp Tumor Res 22: 190-274, 1978.

61. Nakashima RA, Paggi MG and Pedersen PL: Contributions of glycolysis and oxidative phosphorylation to adenosine 5'-triphosphate production in AS-30D hepatoma cells. Cancer Res 44: 5702-5706, 1984.
62. Levine AJ and Puzio-Kuter AM: The control of the metabolic switch in cancers by oncogenes and tumor suppressor genes. Science 330: 1340-1344, 2010.

63. Ulrey CL, Liu L, Andrews LG and Tollefsbol TO: The impact of metabolism on DNA methylation. Hum Mol Genet 14: R139-R147, 2005.

64. Hoffman RM: Altered methionine metabolism, DNA methylation and oncogene expression in carcinogenesis. A review and synthesis. Biochim Biophys Acta 738: 49-87, 1984.

65. Chiang CP, Lang MJ, Liu BY, Wang JT, Leu JS, Hahn LJ and Kuo MY: Expression of proliferating cell nuclear antigen (PCNA) in oral submucous fibrosis, oral epithelial hyperkeratosis and oral epithelial dysplasia in Taiwan. Oral Oncol 36: 353-359, 2000.

66. Lv Q, Zhang J, Yi Y, Huang Y, Wang Y, Wang Y and Zhang W: Proliferating cell nuclear antigen has an association with prognosis and risks factors of cancer patients: A systematic review. Mol Neurobiol: Nov 12, 2015 (Epub ahead of print).

67. Chuang LS, Ian HI, Koh TW, Ng HH, Xu G and Li BF: Human DNA-(cytosine-5) methyltransferase-PCNA complex as a target for p21WAF1. Science 277: 1996-2000, 1997.

68. Whitesell L and Lindquist SL: HSP90 and the chaperoning of cancer. Nat Rev Cancer 5: 761-772, 2005.

69. Workman P and Powers MV: Chaperoning cell death: A critical dual role for Hsp90 in small-cell lung cancer. Nat Chem Biol 3: 455-457, 2007. 